\title{
Endoscopic removal of nucleus pulposus of intervertebral disc on lumbar intervertebral disc protrusion and the influence on inflammatory factors and immune function
}

\author{
GANG XU ${ }^{1}$, CHANGCHUN ZHANG $^{1}, \mathrm{KUN} \mathrm{ZHU}^{1}$, ZHENGQI BAO $^{1}$, \\ PINGHUI ZHOU ${ }^{1}$ and XIAOJUN LI $^{2}$ \\ ${ }^{1}$ Department of Orthopedics, The First Affiliated Hospital of Bengbu Medical College, Bengbu, Anhui 233004; \\ ${ }^{2}$ Department of Spine, Wuxi Traditional Chinese Medicine Hospital, Wuxi, Jiangsu 214071, P.R. China
}

Received June 24, 2019; Accepted November 4, 2019

DOI: $10.3892 /$ etm.2019.8223

\begin{abstract}
Endoscopic removal of nucleus pulposus (NP) of intervertebral disc (IVD) on lumbar intervertebral disc protrusion (LIDP) and its influence on inflammatory factors and immune function were explored. A total of 145 patients with LIDP admitted to The First Affiliated Hospital of Bengbu Medical College from June 2017 to December 2018 were selected and electively treated, in which 87 patients were treated with fenestration discectomy (fenestration group) and 58 patients were treated with endoscopic removal of NP of IVD (minimally invasive group). Effects on patients in the two groups within 6 months after surgery were evaluated by modified MacNab score; differences in surgical related indexes and incidence rates of complications between the two groups were compared; the Oswestry dysfunction score and VAS pain score before treatment, and 1,3 and 6 months after treatment, and changes of cellular levels of TNF- $\alpha$, IL-4, IL-6, $\mathrm{CD}^{+}, \mathrm{CD}^{+}$, and $\mathrm{CD}^{+}$before treatment, and 24 and $48 \mathrm{~h}$ after surgery were evaluated. Length of surgical incision, intraoperative blood loss, time of operation, time in bed, and hospital stays of patients in minimally invasive group were lower than those in the fenestration group $(\mathrm{P}<0.05)$. The Oswestry score and VAS score of patients in minimally invasive group 1, 3 and 6 months after surgery were lower than those in fenestration group $(\mathrm{P}<0.05)$. The incidence rate of spinal instability and overall incidence of complications of patients in minimally invasive group were significantly lower
\end{abstract}

Correspondence to: Dr Xiaojun Li, Department of Spine, Wuxi Traditional Chinese Medicine Hospital, 8 Zhongnan West Road, Wuxi, Jiangsu 214071, P.R. China

E-mail: xbhp15@163.com

Key words: endoscopic removal of nucleus pulposus of intervertebral disc, lumbar intervertebral disc protrusion, inflammatory factors, immune function than those in fenestration group $(\mathrm{P}<0.05)$. Levels of TNF- $\alpha$ and IL-6 of patients in the minimally invasive group 24 and $48 \mathrm{~h}$ after surgery were lower than those in the fenestration group $(\mathrm{P}<0.05)$ and cellular levels of $\mathrm{IL}_{-} 4, \mathrm{CD}^{+}, \mathrm{CD}^{+}$, and $\mathrm{CD}^{+}$ were higher $(\mathrm{P}<0.05)$. In conclusion, endoscopic removal of NP of IVD has good therapeutic effects in patients with LIDP. It reduces inflammation and suppresses immune function with higher safety, worthwhile for clinical use.

\section{Introduction}

Lumbar intervertebral disc protrusion (LIDP) is usually caused by degenerative changes of contents of intervertebral disc (IVD), such as nucleus pulposus (NP) and annulus fibrosus, it often occurs in the posterolateral region and is the main cause of low back pain. It shows high incidence rate and causes high medical expenses, thus increasing social and family burdens $(1,2)$. Lumbar discectomy is still one of the best choices for patients who failed in conservative treatment, and advantages of surgical treatment include its quick effects on the improvement of symptoms and its good long-term efficacy $(3,4)$. However, the incidence rate of reherniation of IVD in patients undergoing surgery is still 3-18\%, which is the most important reason for most patients to receive lumbar discectomy again, and patients are 10 times more likely to have future spinal surgery than standard care patients $(5,6)$. Therefore, choices of surgical methods are of great significance in clinical practice.

Traditional fenestration discectomy involves a large number of normal bones, muscle tissues, and small joints, which causes great damage to the stability of spinal structure of patients. Lumbar segmental instability is one of the causes of failure of lumbar surgery $(7,8)$. With the continuous development of minimally invasive amplification technology and the renewal of minimally invasive concepts, minimally invasive surgery has been applied to various surgical treatments and has achieved good effects (9). The application of endoscopic discectomy in the clinical treatment of lumbar intervertebral disc protrusion (LIDP) is increasing, which significantly reduces the damage to patients and maximizes the stability of 
the spinal structure $(10,11)$. However, its efficacy has not been widely recognized clinically.

Therefore, this study analyzed effects of endoscopic removal of NP of IVD on LIDP again, as well as its influences on inflammatory factors and immune function, so as to provide references for clinical treatment of LIDP.

\section{Patients and methods}

Objects of study. A total of 145 patients with LIDP aged between 30 and 60 years were admitted to The First Affiliated Hospital of Bengbu Medical College (Bengbu, China) from June 2017 to December 2018 were selected and were electively treated. Patients were divided into two groups according to different treatment methods. There were 87 patients treated with fenestration discectomy (fenestration group) and 58 patients treated with endoscopic removal of NP of IVD (minimally invasive group). The inclusion criteria were as follows: Patients diagnosed as LIDP by X-ray imaging and met the diagnostic criteria of LIDP (12); patients failed in conservative treatment, with no spondylolisthesis and spinal stenosis. The exclusion criteria were as follows: Patients experienced recurrence of LIDP, or with previous history of surgery and multi-segmental protrusion of IVD; patients with LIDP combined with diabetes, hypertension, congenital spinal deformity, greater bone compression, bone metabolic disease, tumor, severe infection, hemophilia or other coagulation diseases.

This study was approved by the Medical Ethics Committee of The First Affiliated Hospital of Bengbu Medical College. Signed informed consents were obtained from the patients or the guardians.

Surgical methods. Patients in the fenestration group underwent general anesthesia in lateral posture. The location of lesion was localized by X-ray after successful anesthesia. The skin was incised on the fourth to the first spinous process. Surrounding tissues were bluntly separated to show ligamentum flavum, and en bloc excision of ligamentum flavum was performed. Nerve roots and dura mater were separated by epidural detacher; longitudinal ligament and annulus fibrosus were cut after exposing IVD; herniated NP was pulled out by nerve root retractor; diseased tissues were removed and the blood was stopped from flowing. Local anesthesia was adopted in the minimally invasive group. The needle was inserted into vertebral posterior or the center of the pedicle of vertebral arch under the guidance of X-ray, and the needle was inserted through the intervertebral foramen to the intervertebral space [2 ml suspension of omnipaque and methylthioniniumchloride $(6: 1)]$; and then radiography was performed, guidewire was inserted, puncture needles were out and catheter was put in; devices such as intervertebral foramen were connected, the working channel of intervertebral foramen was $8 \mathrm{~mm}$; flocculent substances and fat were cleaned; loose NP was removed and the blood was stopped from flowing after no leakage.

Observation indicators. The efficacy of patients in the two groups within 6 months after surgery was evaluated by the modified MacNab score. Differences in surgical related indexes (length of incision, intraoperative blood loss, time of operation, time in bed, hospital stays) of patients were compared between the two groups. The Oswestry dysfunction score (pain in back and loin, leg pain, ability of daily life, lifting, walking, sitting, standing) and VAS pain score of patients were evaluated before surgery and 1,3 and 6 months after surgery. The incidence rate of complications of patients was counted in the two groups. Changes of inflammatory factors (TNF- $\alpha$, IL-4, IL-6) and immune function $\left(\mathrm{CD}^{+}\right.$, $\mathrm{CD}^{+}$and $\mathrm{CD}^{+}$cells) of patients between the two groups were compared before surgery, 24 and $48 \mathrm{~h}$ after surgery.

Detection methods. The fasting peripheral blood of patients was collected in the early morning. After heparin anticoagulation, serum was centrifuged at $100 \mathrm{x} \mathrm{g}$ at $4^{\circ} \mathrm{C}$ for $10 \mathrm{~min}$ to detect inflammatory factors of patients. Levels of TNF- $\alpha$, IL-4 and IL-6 were all detected by ELISA. The detection kits were purchased from Abcam, with cat. nos. ab181421, ab46022 and ab46027, respectively. Altogether $20 \mu \mathrm{l}$ samples or standard products were added into 96-well plates and negative controls were set. Each sample was provided with three parallel wells, water bath was carried out at $37^{\circ} \mathrm{C}$ for $30 \mathrm{~min}$ after sealing the membrane, excess liquid was poured out, washing buffer was used 3 times, each time for $30 \mathrm{sec}$, and enzyme-labeled antibody was added. Then, the above steps were repeated for incubation and washing, $50 \mu \mathrm{l}$ of developer A and B were successively added, they were developed at $37^{\circ} \mathrm{C}$ in the dark for $15 \mathrm{~min}, 50 \mu \mathrm{l}$ of stopping solution was added to terminate the reaction, absorbance of the samples was measured within 15 min with $450 \mathrm{~nm}$ measuring wavelength. The microplate reader was purchased from Beijing Putian Xinqiao Technology Co., Ltd. CD ${ }^{+}, \mathrm{CD}^{+}$ and $\mathrm{CD}^{+}$cells were detected by Attune NxT flow cytometer and purchased from Thermo Fisher Scientific, Inc., and relevant reagents and instruments were supplied by Thermo Fisher Scientific, Inc.

Statistical analysis. SPSS 19.0 (SPSS, Inc., Chicago, IL, USA) was adopted. The measurement data were expressed as [n (\%)], and comparison of ratios between the two groups was tested by $\chi^{2}$ test. The enumeration data were expressed as mean \pm standard deviation (mean $\pm \mathrm{SD}$ ), and the comparison between the two groups was performed by independent-samples t-test. The comparison of different time points in the group was performed by repeated measures analysis of variance, and the post hoc test was performed by LSD test. $\mathrm{P}<0.05$ was considered to indicate a statistically significant difference.

\section{Results}

General data. There were 87 patients in the fenestration group, including 48 males (55.17\%) and 39 females (44.83\%), aged $36.75 \pm 5.48$ years. There were 58 patients in the minimally invasive group, including 34 males $(58.62 \%)$ and 24 females $(41.38 \%)$, aged $38.16 \pm 5.93$ years. There were no statistical differences in ratios of sex and age between the two groups $(\mathrm{P}>0.05)$, neither any significant difference in other data such as body mass index (BMI), course of disease, and pathological segments between them $(\mathrm{P}>0.05)$ (Table I).

Clinical efficacy. There were no significant differences in rates of excellent, good, acceptable, and poor efficacy of patients between the two groups ( $\mathrm{P}>0.05)$ (Table II). 
Table I. General data.

\begin{tabular}{|c|c|c|c|c|}
\hline Variables & $\begin{array}{l}\text { Fenestration } \\
\text { group }(n=87)\end{array}$ & $\begin{array}{l}\text { Minimally invasive } \\
\text { group }(n=58)\end{array}$ & $\chi^{2 / t}$ & P-value \\
\hline $\operatorname{Sex}[\mathrm{n}(\%)]$ & & & 0.168 & 0.682 \\
\hline Male & $48(55.17)$ & $34(58.62)$ & & \\
\hline Female & $39(44.83)$ & $24(41.38)$ & & \\
\hline Age (years) & $36.75 \pm 5.48$ & $38.16 \pm 5.93$ & 1.469 & 0.144 \\
\hline BMI $\left(\mathrm{kg} / \mathrm{m}^{2}\right)$ & $23.75 \pm 3.14$ & $23.48 \pm 3.86$ & 0.462 & 0.645 \\
\hline Course of disease (years) & $1.04 \pm 0.12$ & $1.06 \pm 0.14$ & 0.919 & 0.360 \\
\hline Pathologic segments [n (\%)] & & & 1.394 & 0.498 \\
\hline L3-L4 & $10(11.49)$ & $6(10.34)$ & & \\
\hline L4-L5 & $45(51.72)$ & $25(43.10)$ & & \\
\hline L5-S1 & $32(36.78)$ & $27(46.55)$ & & \\
\hline Prominent types [n (\%)] & & & 0.065 & 0.799 \\
\hline Central type & $18(20.69)$ & $11(18.97)$ & & \\
\hline Peripheral type & $69(79.31)$ & $47(81.03)$ & & \\
\hline Straight leg raising test $[\mathrm{n}(\%)]$ & & & 0.115 & 0.734 \\
\hline Positive & $44(50.57)$ & $31(53.45)$ & & \\
\hline Negative & $43(49.43)$ & $27(46.55)$ & & \\
\hline Combined with paresthesia [n (\%)] & & & 0.105 & 0.746 \\
\hline Yes & $19(21.84)$ & $14(24.14)$ & & \\
\hline No & $68(78.16)$ & $44(75.86)$ & & \\
\hline Combined with abnormal movements [n (\%)] & & & 0.070 & 0.791 \\
\hline Yes & $15(17.24)$ & $11(18.97)$ & & \\
\hline No & $72(82.76)$ & $47(81.03)$ & & \\
\hline
\end{tabular}

BMI, body mass index.

Table II. Analysis of clinical efficacy of patients in the two groups [n (\%)].

\begin{tabular}{|c|c|c|c|c|}
\hline Variables & Fenestration group $(n=87)$ & Minimally invasive group $(n=58)$ & $\chi^{2}$ & P-value \\
\hline Excellent & $46(52.87)$ & $36(62.07)$ & 1.198 & 0.274 \\
\hline Good & $28(32.18)$ & $17(29.31)$ & 0.134 & 0.714 \\
\hline Acceptable & $9(10.34)$ & $4(6.90)$ & 0.507 & 0.476 \\
\hline Poor & $4(4.60)$ & $1(1.72)$ & 0.863 & 0.353 \\
\hline
\end{tabular}

Analysis of surgical related indicators. Length of surgical incision, intraoperative blood loss, time of operation, time in bed, and hospital stays of patients in minimally invasive group were lower than those in fenestration group $(\mathrm{P}<0.05)$ (Fig. 1).

Analysis of Oswestrydysfunction. There were no statistical differences in the Oswestry score of patients between the two groups before surgery $(\mathrm{P}>0.05)$. The Oswestry score of patients in the two groups continuously decreased 1, 3 and 6 months after surgery $(\mathrm{P}<0.05)$, and the Oswestry score of patients in minimally invasive group was lower than those in fenestration group 1,3 and 6 months after surgery $(\mathrm{P}<0.05)$ (Fig. 2).

Results of VAS score. There were no significant differences in the VAS score of patients between the two groups before surgery $(\mathrm{P}>0.05)$. The VAS score of patients in the two groups continuously decreased 1,3 and 6 months after surgery $(\mathrm{P}<0.05)$, and the VAS score of patients in the minimally invasive group was lower than those in the fenestration group 1, 3 and 6 months after surgery $(\mathrm{P}<0.05)$ (Fig. 3).

Analysis of the incidence rate of complications in the two groups. The incidence rate of spinal instability of patients in minimally invasive group was significantly lower than that in fenestration group $(\mathrm{P}<0.05)$. There were no statistical differences in the incidence rate of incision infection and transient nerve paralysis $(\mathrm{P}>0.05)$. The incidence rate of complications of patients was also higher than that in minimally invasive group $(\mathrm{P}<0.05)$ (Table III).

Analysis of levels of inflammatory factors after surgery of patients in the two groups. Levels of TNF- $\alpha$, IL-4 and IL-6 of 
Table III. Analysis of incidence rate of complications of patients in the two groups [n (\%)].

\begin{tabular}{lccr}
\hline Variables & Fenestration group $(\mathrm{n}=87)$ & Minimally invasive group $(\mathrm{n}=58)$ & $\chi^{2}$ \\
\hline Incision infection & $7(8.05)$ & $3(5.17)$ & 0.448 \\
Transient nerve paralysis & $10(11.49)$ & $2(3.45)$ & 0.504 \\
Spinal instability & $7(8.05)$ & $0(0.00)$ & 0.157 \\
Total complications & $24(27.59)$ & $5(8.62)$ & 0.042 \\
\end{tabular}
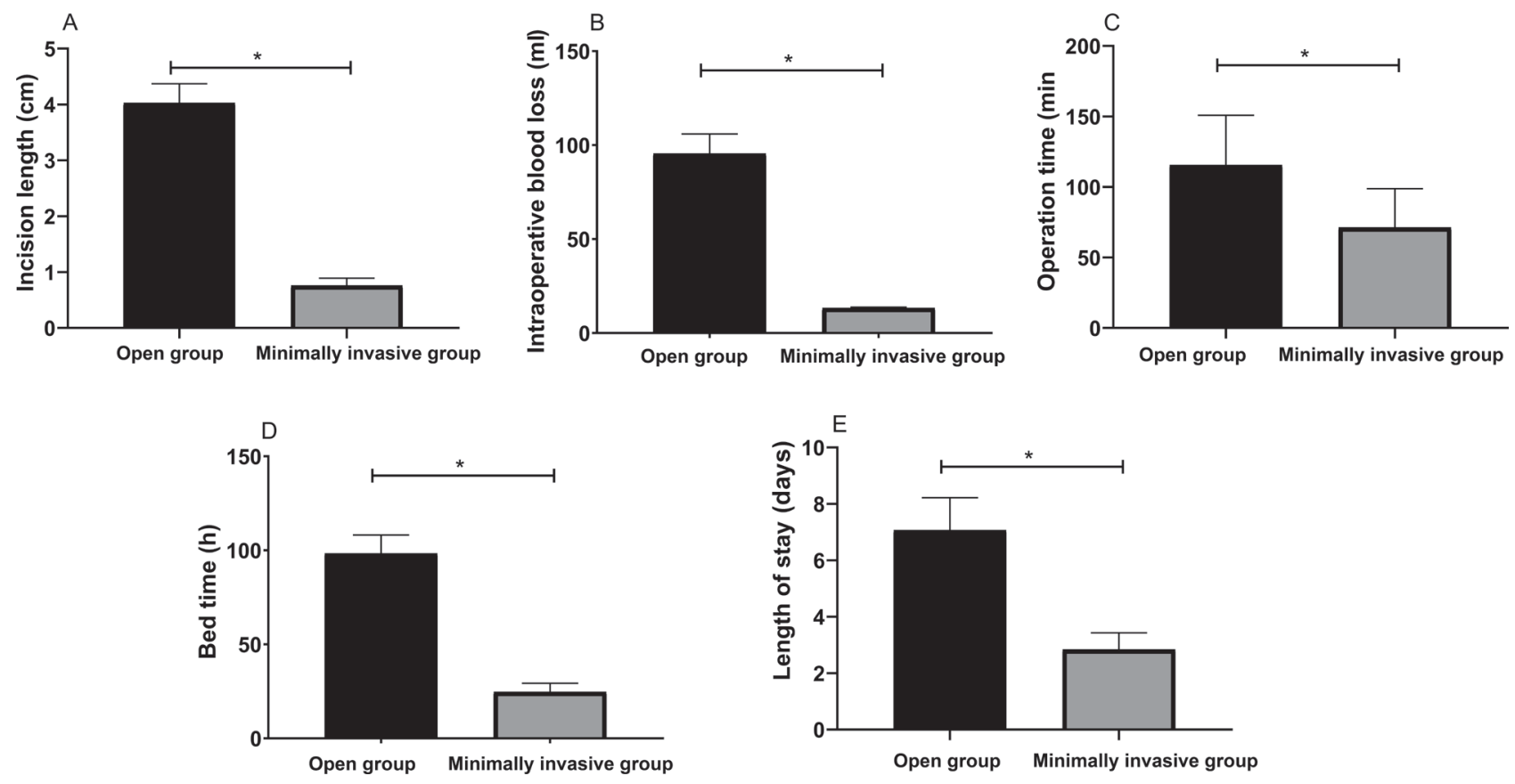

Figure 1. Analysis of surgical related indicators. (A) Length of surgical incision. (B) The amount of intraoperative blood loss (C) Time of operation. (D) Time in bed. (E) Hospital stays. ${ }^{*} \mathrm{P}<0.05$.

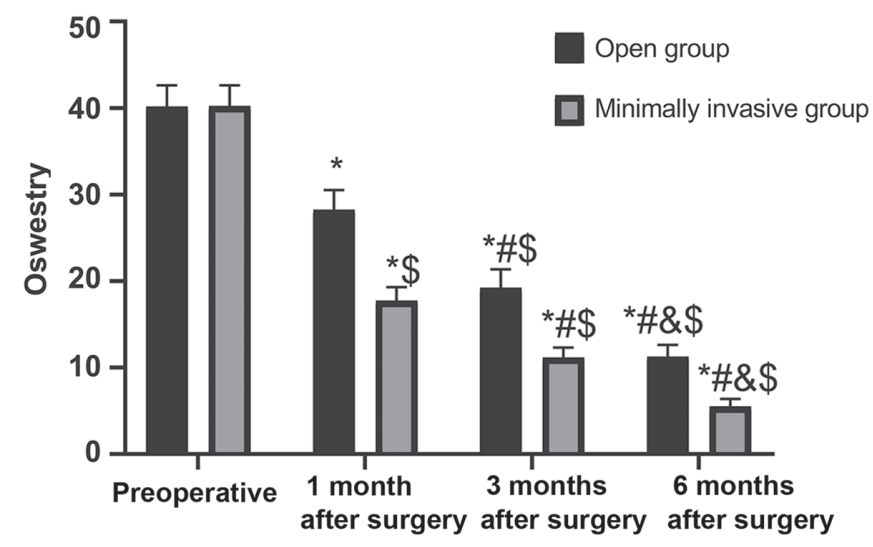

Figure 2. Analysis of Oswestry dysfunction. " $\mathrm{P}<0.05$ compared with that of before surgery; ${ }^{\#} \mathrm{P}<0.05$ compared with that of 1 month after surgery; ${ }^{\&} \mathrm{P}<0.05$ compared with that of 3 months after surgery; ${ }^{\$} \mathrm{P}<0.05$ in the fenestration group at same time.

patients in the two groups were not significantly different before surgery $(\mathrm{P}>0.05)$. Levels of TNF- $\alpha$ and IL-6 of patients in the two groups continuously decreased 24 and $48 \mathrm{~h}$ after surgery $(\mathrm{P}<0.05)$. Levels of IL-4 continued to rise $(\mathrm{P}<0.05)$; however, levels of TNF- $\alpha$ and IL- 6 of patients in minimally invasive

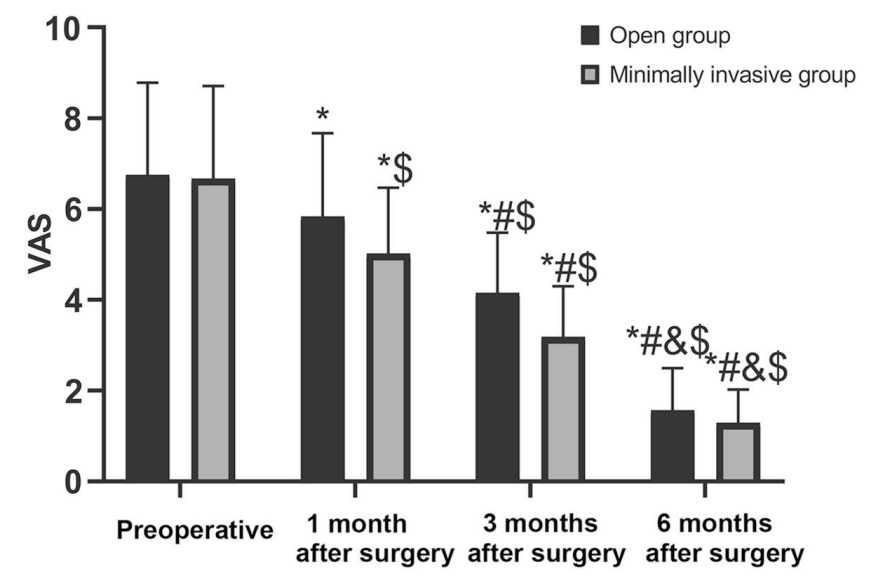

Figure 3. VAS scores. ${ }^{*} \mathrm{P}<0.05$ compared with that of before surgery; ${ }^{\#} \mathrm{P}<0.05$ compared with that of 1 month after surgery; ${ }^{\circledR} \mathrm{P}<0.05$ compared with that of 3 months after surgery; ${ }^{\$} \mathrm{P}<0.05$ in the fenestration group at the same time.

group after surgery were lower than those in fenestration group $(\mathrm{P}<0.05)$ and levels of IL-4 were higher $(\mathrm{P}<0.05)$ (Table IV).

Changes in postoperative immune function of patients in the two groups. There were no statistical differences in cellular 
Table IV. Analysis of levels of inflammatory factors after surgery of patients in the two groups (pg/ml).

\begin{tabular}{|c|c|c|c|c|}
\hline Variables & Fenestration group $(n=87)$ & Minimally invasive group $(\mathrm{n}=58)$ & $\mathrm{t}$ & P-value \\
\hline \multicolumn{5}{|l|}{ TNF- $\alpha$} \\
\hline Before surgery & $90.24 \pm 9.64$ & $91.19 \pm 9.14$ & 0.593 & 0.554 \\
\hline $24 \mathrm{~h}$ after surgery & $68.42 \pm 5.25^{\mathrm{a}}$ & $50.13 \pm 4.86^{\mathrm{a}}$ & 21.164 & $<0.001$ \\
\hline $48 \mathrm{~h}$ after surgery & $51.24 \pm 3.43^{\mathrm{a}, \mathrm{b}}$ & $20.02 \pm 2.73^{\mathrm{a}, \mathrm{b}}$ & 58.106 & $<0.001$ \\
\hline \multicolumn{5}{|l|}{ IL-4 } \\
\hline Before surgery & $24.28 \pm 3.12$ & $23.83 \pm 2.87$ & 0.878 & 0.381 \\
\hline $24 \mathrm{~h}$ after surgery & $35.22 \pm 3.02^{\mathrm{a}}$ & $46.48 \pm 1.85^{\mathrm{a}}$ & 25.381 & $<0.001$ \\
\hline $48 \mathrm{~h}$ after surgery & $40.24 \pm 1.88^{\mathrm{a}, \mathrm{b}}$ & $49.22 \pm 1.83^{\mathrm{a}, \mathrm{b}}$ & 28.477 & $<0.001$ \\
\hline \multicolumn{5}{|l|}{ IL-6 } \\
\hline Before surgery & $234.58 \pm 28.64$ & $233.76 \pm 27.15$ & 0.172 & 0.863 \\
\hline $24 \mathrm{~h}$ after surgery & $164.73 \pm 20.42^{\mathrm{a}}$ & $131.68 \pm 17.15^{\mathrm{a}}$ & 10.163 & $<0.001$ \\
\hline $48 \mathrm{~h}$ after surgery & $92.19 \pm 14.32^{\mathrm{a}, \mathrm{b}}$ & $60.47 \pm 12.36^{\mathrm{a}, \mathrm{b}}$ & 13.787 & $<0.001$ \\
\hline
\end{tabular}

${ }^{\mathrm{a}} \mathrm{P}<0.05$ compared with that of before surgery; ${ }^{\mathrm{b}} \mathrm{P}<0.05$ compared with that of $24 \mathrm{~h}$ after surgery.

Table V. Changes in postoperative immune function of patients in the two groups (\%).

\begin{tabular}{|c|c|c|c|c|}
\hline Variables & Fenestration group $(n=87)$ & Minimally invasive group $(\mathrm{n}=58)$ & $\mathrm{t}$ & P-value \\
\hline \multicolumn{5}{|l|}{ CD3 } \\
\hline Before surgery & $58.67 \pm 14.75$ & $59.43 \pm 13.43$ & 0.315 & 0.753 \\
\hline $24 \mathrm{~h}$ after surgery & $51.36 \pm 10.57^{\mathrm{a}}$ & $55.83 \pm 11.39^{\mathrm{a}}$ & 2.398 & 0.018 \\
\hline $48 \mathrm{~h}$ after surgery & $55.85 \pm 10.42^{\mathrm{b}}$ & $59.86 \pm 10.27^{\mathrm{b}}$ & 2.283 & 0.024 \\
\hline \multicolumn{5}{|l|}{ CD4 } \\
\hline Before surgery & $31.47 \pm 7.66$ & $30.75 \pm 8.15$ & 0.540 & 0.590 \\
\hline $24 \mathrm{~h}$ after surgery & $24.13 \pm 9.07^{\mathrm{a}}$ & $28.48 \pm 8.39^{\mathrm{a}}$ & 2.914 & 0.004 \\
\hline $48 \mathrm{~h}$ after surgery & $29.17 \pm 9.83^{b}$ & $32.82 \pm 11.28^{\mathrm{b}}$ & 2.064 & 0.041 \\
\hline \multicolumn{5}{|l|}{ CD8 } \\
\hline Before surgery & $25.12 \pm 9.17$ & $25.85 \pm 9.22$ & 0.524 & 0.601 \\
\hline $24 \mathrm{~h}$ after surgery & $16.04 \pm 7.25^{\mathrm{a}}$ & $20.79 \pm 8.64^{\mathrm{a}}$ & 3.928 & $<0.001$ \\
\hline $48 \mathrm{~h}$ after surgery & $12.87 \pm 5.69^{\mathrm{a}, \mathrm{b}}$ & $17.13 \pm 6.11^{\mathrm{a}, \mathrm{b}}$ & 4.759 & $<0.001$ \\
\hline
\end{tabular}

${ }^{\mathrm{a}} \mathrm{P}<0.05$ compared with that of before surgery; ${ }^{\mathrm{b}} \mathrm{P}<0.05$ compared with that of $24 \mathrm{~h}$ after surgery.

levels of $\mathrm{CD}^{+}, \mathrm{CD}^{+}$, and $\mathrm{CD}^{+}$of patients between the two groups before surgery $(\mathrm{P}>0.05)$. Cellular levels of $\mathrm{CD}^{+}$, $\mathrm{CD}^{+}$, and $\mathrm{CD}^{+}$in the two groups $24 \mathrm{~h}$ after surgery were lower than those before surgery $(\mathrm{P}<0.05) . \mathrm{CD}^{+}$and $\mathrm{CD}^{+}$ cells in the two groups $48 \mathrm{~h}$ after surgery recovered to preoperative similar level $(\mathrm{P}>0.05)$, which were higher than those at $24 \mathrm{~h}$ after surgery $(\mathrm{P}<0.05)$. But cellular levels of $\mathrm{CD}^{+}$ continued to decrease $(\mathrm{P}<0.05)$. Cellular levels of $\mathrm{CD}^{+}, \mathrm{CD}^{+}$, and $\mathrm{CD}^{+}$of patients in minimally invasive group were higher than those in fenestration group 24 and $48 \mathrm{~h}$ after surgery $(\mathrm{P}<0.05)($ Table V).

\section{Discussion}

LIDP is an increasingly serious public health problem characterized by increased fibrosis, decreased content of proteins and polysaccharides, reduced ability of tissue binding and water retention, and impaired mechanical properties of the motor segment. Its recurrence rate ranges from 5 to $25 \%(13,14)$. Safe and effective surgical treatment of LIDP is of great importance to surgeons. Minimally invasive surgery has always been an important research direction for surgical treatment. This study analyzed the therapeutic value of endoscopic discectomy in patients with LIDP.

The results of this study showed that there were no differences in clinical effects of the two surgical methods, but the incidence rate of postoperative complications after minimally invasive surgery was significantly lower than that after fenestration surgery, especially the incidence rate of spinal instability. Spinal instability is the main complication after surgery of fenestration discectomy. Fenestration discectomy requires extensive resection of bone tissues and ligaments, so 
patients after it often require fixation of additional surgical instruments to reduce postoperative spinal instability (15), which can be avoided with endoscopic discectomy. The spinal canal can fully enter the midline of the spinal canal without extensive resection of the small joint or adjacent pedicle. In the present study of Li et al (16), IVD total endoscopic surgery of L5/S1 through lamina was a safe, reasonable and effective minimally invasive spinal surgery technique with good short-term clinical efficacy. Similar results were reported in another study (17). There were no significant changes in the height of IVD of patients under percutaneous endoscopic lumbar discectomy, and the height of IVD was significantly reduced from $23.7 \pm 3.3$ to $19.1 \pm 3.7$ in patients with fenestration discectomy. The study also showed that the minimally invasive group experienced significantly shorter time of surgery, hospitalization and returning to work, which was similar to our results. Our results also showed that the length of incision, amount of intraoperative blood loss, time of operation, time in bed, and hospital stays in minimally invasive group were lower than those in fenestration group. Similar conclusions were found in the study of Garg et al (18): The amount of bleeding and hospital stays were significantly shorter in patients undergoing microendoscopic discectomy. These indicators are related to surgical safety. Chen et al (19) indicated that percutaneous endoscopic discectomy had better safety and was associated with less blood loss, shorter hospital stays, and short incision, and was the best choice for patients with LIDP. Pan et al (20) also compared endoscopic lumbar discectomy with traditional lumbar discectomy in patients with LIDP. In their results, patients in the endoscope group were significantly more satisfied with the treatment than those in the traditional treatment group, and the bleeding volume, hospital stays, and wound size in the endoscope group were also smaller than those in the traditional treatment group. In addition, they also found that the improvement of inflammatory cytokines IL-6 and CPR in the endoscope group at 24 and $48 \mathrm{~h}$ after surgery was significantly better than that in the traditional treatment group, which was similar to our results. However, they did not find any difference in the incidence rate of complications between the two groups. Only one case of numb nerve occurred in the endoscope group and recovered after 2 weeks, while no complications occurred in the traditional treatment group. The incidence rate of complications after discectomy reportedly ranges from 13.2 to $19.3 \%$ (21), which requires further analysis of more factors, such as the proficiency of surgical operators, surgical approach, postoperative nursing and so on.

Another interesting finding of this study was that patients in minimally invasive group had lower levels of postoperative inflammatory response and faster immune function recovery. Chang et al (22) drew similar conclusions in their study. The levels of inflammatory factors TNF- $\alpha$ and CRP in patients undergoing percutaneous endoscopic lumbar discectomy were also significantly lower than those in patients undergoing open discectomy. We speculated that this was related to postoperative pain in patients. Pain of the patients with IVD protrusion after the NP removal was reduced, the compression nerve and the local inflammation caused by it were also reduced. Therefore, the degree of inflammation is an indirect indicator for judging effects of surgery (23). In some studies, it has been reported that increased inflammatory response caused by surgical stress is an important cause of postoperative pain in patients because inflammatory factors are also important mediators of pain (24). In a basic study, pain behavior was increased after injection of TNF- $\alpha$ in IVD puncture model of mice (25). The Oswestry score can assess functions of pain in back and loin, leg pain, ability of daily life, lifting, walking, sitting, and standing (26). In our results, the Oswestry score in the minimally invasive group was significantly better than those in fenestration group at 1,3 and 6 months after surgery. Results of further analysis of pain also showed that the degree of postoperative pain of patients in minimally invasive group was significantly lower than that in fenestration group. In the study of Liu and Wang (27), it was also found that percutaneous endoscopic discectomy could effectively treat LIDP, which was beneficial to reduce pain and inflammation. However, there are few reports on effects of these two surgical methods on postoperative immune function. Postoperative pain could cause immunosuppression and lead to decreased immune function in patients (28). The minimally invasive group experienced lower postoperative pain, so the degree of inhibition of immune function was lower. This result was also confirmed by our studies. Although cellular levels of $\mathrm{CD}^{+}, \mathrm{CD}^{+}$, and $\mathrm{CD} 8^{+}$in the two groups were decreased $24 \mathrm{~h}$ after surgery, the minimally invasive group had significantly higher levels than the fenestration group.

The deficiency of this study was that a prospective analysis was adopted. Although we set strict inclusion criteria, there still may be some bias in the inclusion process of patients. This study only analyzed the short-term efficacy of patients in the two groups, and the long-term efficacy results still need further tracking.

In conclusion, endoscopic removal of NP of IVD has good therapeutic effects in patients with LIDP, and can reduce inflammation and suppression of immune function with higher safety, which is worthy of clinical use.

\section{Acknowledgements}

Not applicable.

\section{Funding}

This study was supported by the Study on Degenerative Intervertebral Disc of Pulposus and Mesenchymal Stem Cells Transfected with Injectable Hydrogels Carrying Lentiviruses of General Program of Natural Science Foundation of Anhui Province in 2019 (project no. 1908085MC90).

\section{Availability of data and materials}

The datasets used and/or analyzed during the present study are available from the corresponding author on reasonable request.

\section{Authors' contributions}

GX observed the indicators and wrote the manuscript. XL interpreted and analyzed the patient data. $\mathrm{CZ}$ and $\mathrm{KZ}$ designed the study and performed the experiments. ZB and PZ were responsible for the analysis and discussion of the data. All the authors read and approved the final manuscript. 


\section{Ethics approval and consent to participate}

This study was approved by the Medical Ethics Committee of The First Affiliated Hospital of Bengbu Medical College (Bengbu, China). Signed informed consents were obtained from the patients or the guardians.

\section{Patient consent for publication}

Not applicable.

\section{Competing interests}

The authors declare that they have no competing interests.

\section{References}

1. Sun D, Liu P, Cheng J, Ma Z, Liu J and Qin T: Correlation between intervertebral disc degeneration, paraspinal muscle atrophy, and lumbar facet joints degeneration in patients with lumbar disc herniation. BMC Musculoskelet Disord 18: 167, 2017.

2. Messner A, Stelzeneder D, Trattnig S, Welsch GH, Schinhan M, Apprich S, Brix M, Windhager R and Trattnig S: Does T2 mapping of the posterior annulus fibrosus indicate the presence of lumbar intervertebral disc herniation? A 3.0 Tesla magnetic resonance study. Eur Spine J 26: 877-883, 2017.

3. Lurie JD, Tosteson TD, Tosteson AN, Zhao W, Morgan TS, Abdu WA, Herkowitz H and Weinstein JN: Surgical versus nonoperative treatment for lumbar disc herniation: Eight-year results for the spine patient outcomes research trial. Spine 39 3-16, 2014.

4. Atlas SJ, Keller RB, Wu YA, Deyo RA and Singer DE: Long-term outcomes of surgical and nonsurgical management of sciatica secondary to a lumbar disc herniation: 10 year results from the Maine lumbar spine study. Spine 30: 927-935, 2005.

5. Leven D, Passias PG, Errico TJ, Lafage V, Bianco K, Lee A, Lurie JD, Tosteson TD, Zhao W, Spratt KF, et al: Risk factors for reoperation in patients treated surgically for intervertebral disc herniation: A subanalysis of eight-year SPORT data. J Bone Joint Surg Am 97: 1316-1325, 2015.

6. Huang W, Han Z, Liu J, Yu L and Yu X: Risk factors for recurrent lumbar disc herniation: A systematic review and meta-analysis. Medicine (Baltimore) 95: e2378, 2016.

7. Majeed SA, Vikraman CS, Mathew V and S AT: Comparison of outcomes between conventional lumbar fenestration discectomy and minimally invasive lumbar discectomy: An observational study with a minimum 2-year follow-up. J Orthop Surg Res 8: 34, 2013.

8. Mascarenhas AA, Thomas I, Sharma G and Cherian JJ: Clinical and radiological instability following standard fenestration discectomy. Indian J Orthop 43: 347-351, 2009.

9. Norton MJ and Ischy ND: Apparatus and method for minimally invasive surgery. US Patent 9,820,771(P). Filed on March 3, 2006; issued November 21, 2017.

10. Kim JS, Jung B and Lee SH: Instrumented minimally invasive spinal-transforaminal lumbar interbody fusion (MIS-TLIF). Clin Spine Surg 31: E302-E309, 2018.

11. Phan K and Mobbs RJ: Minimally invasive versus open laminectomy for lumbar stenosis: A systematic review and meta-analysis. Spine 41: E91-E100, 2016.

12. Kreiner DS, Hwang SW, Easa JE, Resnick DK, Baisden JL, Bess S, Cho CH, DePalma MJ, Dougherty P II, Fernand R, et al; North American Spine Society: An evidence-based clinical guideline for the diagnosis and treatment of lumbar disc herniation with radiculopathy. Spine J 14: 180-191, 2014.
13. Gorth DJ, Shapiro IM and Risbud MV: Transgenic mice overexpressing human TNF- $\alpha$ experience early onset spontaneous intervertebral disc herniation in the absence of overt degeneration. Cell Death Dis 10: 7, 2018

14. Vinas-Rios JM, Sanchez-Aguilar M, Medina Govea FA, Von Beeg-Moreno V and Meyer F; DWG Registry-group: Incidence of early postoperative complications requiring surgical revision for recurrent lumbar disc herniation after spinal surgery: A retrospective observational study of 9,310 patients from the German Spine Register. Patient Saf Surg 12: 9, 2018.

15. Regev GJ, Salame K, Behrbalk E, Keynan O and Lidar Z: Minimally invasive transforaminal, thoracic microscopic discectomy: Technical report and preliminary results and complications. Spine J 12: 570-576, 2012.

16. Li ZZ, Hou SX, Shang WL, Song KR and Zhao HL: The strategy and early clinical outcome of full-endoscopic L5/S1 discectomy through interlaminar approach. Clin Neurol Neurosurg 133: 40-45, 2015.

17. Choi KC, Kim JS and Park CK: Percutaneous endoscopic lumbar discectomy as an alternative to open lumbar microdiscectomy for large lumbar disc herniation. Pain Physician 19: E291-E300, 2016.

18. Garg B, Nagraja UB and Jayaswal A: Microendoscopic versus open discectomy for lumbar disc herniation: A prospective randomised study. J Orthop Surg (Hong Kong) 19: 30-34, 2011.

19. Chen P, Hu Y and Li Z: Percutaneous endoscopic transforaminal discectomy precedes interlaminar discectomy in the efficacy and safety for lumbar disc herniation. Biosci Rep 39: BSR20181866, 2019.

20. Pan L, Zhang $\mathrm{P}$ and Yin Q: Comparison of tissue damages caused by endoscopic lumbar discectomy and traditional lumbar discectomy: A randomised controlled trial. Int J Surg 12: 534-537, 2014.

21. Epstein NE: A review of complication rates for anterior cervical diskectomy and fusion (ACDF). Surg Neurol Int 10: 10, 2019.

22. Chang F, Zhang T, Gao G, Yu C, Liu P, Zuo G and Huang X: Therapeutic effect of percutaneous endoscopic lumbar discectomy on lumbar disc herniation and its effect on oxidative stress in patients with lumbar disc herniation. Exp Ther Med 15: 295-299, 2018.

23. Suri P, Pearson AM, Zhao W, Lurie JD, Scherer EA, Morgan TS and Weinstein JN: Pain recurrence after discectomy for symptomatic lumbar disc herniation. Spine 42: 755-763, 2017.

24. Reddi D: Preventing chronic postoperative pain. Anaesthesia 71 (Suppl 1): 64-71, 2016.

25. Lai A, Moon A, Purmessur D, Skovrlj B, Laudier DM, Winkelstein BA, Cho SK, Hecht AC and Iatridis JC: Annular puncture with tumor necrosis factor-alpha injection enhances painful behavior with disc degeneration in vivo. Spine $\mathrm{J} 16$ : 420-431, 2016.

26. Brodke DS, Goz V, Lawrence BD, Spiker WR, Neese A and Hung M: Oswestry Disability Index: A psychometric analysis with 1,610 patients. Spine J 17: 321-327, 2017.

27. Liu SW and Wang XY: Comparison of pain media and inflammatory factors after percutaneous transforaminal endoscopic discectomy and traditional fenestration operation treatment of protrusion of lumbar intervertebral disc. Hainan Yixueyuan Xuebao 23: 108-111, 2017 (In Chinese).

28. Beilin B, Shavit Y, Trabekin E, Mordashev B, Mayburd E, Zeidel A and Bessler $\mathrm{H}$ : The effects of postoperative pain management on immune response to surgery. Anesth Analg 97: 822-827, 2003.

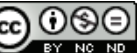

This work is licensed under a Creative Commons Attribution-NonCommercial-NoDerivatives 4.0 International (CC BY-NC-ND 4.0) License. 